\title{
Faktor-Faktor yang Berhubungan dengan Partisipasi Pria dalam Program Keluarga Berencana di Kabupaten Muaro Jambi
}

\section{Factors Related to The Participation of Men in Family Planning Programs in Muaro Jambi District}

\author{
Yun Afrinaldi* , Suandi \& Syafri \\ Jurusan Kependudukan, Fakultas Ilmu Kependudukan dan Ketenagakerjaan, \\ Universitas Jambi, Indonesia
}

Diterima: 06 September 2020; Disetujui: 15 Desember 2020; Diterbitkan: 31 Januari 2021

\begin{abstract}
Abstrak
Tulisan ini bertujuan untuk memperoleh pemahaman tentang gambaran karakteristik pria pasangan usia subur, partisipasinya dalam program KB dan menilai faktor-faktor yang mempengaruhi partisipasi pria tersebut dalam program KB di Kabupaten Muaro Jambi. Masalah dalam penelitian ini difokuskan pada masih rendah dimana tahun 2018 hanya sebesar 1,3\% terdiri dari akseptor kondom sebesar 1,2\% dan akseptor vasektomi (MOP) sebesar 0,1\%. Capaian tersebut sangat tertinggal bila dibanding dengan cakupan Provinsi Jambi sebesar 2,5\%. Kondisi ini menggambarkan masih rendahnya partisipasi pria dalam program KB di Kabupaten Muaro Jambi. Guna mendekati masalah ini dipergunakan acuan dari beberapa faktor - faktor yang mempengaruhi rendahnya partisipasi proda dalam program KB diantaranya faktor predisposisi, faktor pendukung dan faktor pendorong. Data - data dikumpulkan melalui survei wawancara langsung kepada responden menggunakan kuisioner dan dianalisis menggunakan metode kuantitatif dengan pendekatan desain cross sectional. Kajian ini menyimpulkan bahwa pengetahuan merupakan faktor paling dominan berhubungan dengan partisipasi pria dalam program KB di Kabupaten Muaro Jambi. Pria dengan pengetahuan baik tentang KB berpeluang 2,037 kali untuk lebih berpartisipasi dalam program KB dibanding pria dengan pengetahuan rendah tentang KB setelah dikontrol oleh variabel pendidikan, jumlah anak, nilai anak, dan usia pertama kawin.

Kata Kunci: Partisipasi Pria; Keluarga Berencana; Muaro Jambi
\end{abstract}

\begin{abstract}
This paper aims to gain an understanding of the characteristics of male couples of childbearing age, their participation in the family planning program and to assess the factors that influence men's participation in the family planning program in Muaro Jambi District. The problem in this study is focused on the low rate, where in 2018 only $1.3 \%$ consisted of $1.2 \%$ condom acceptors and $0.1 \%$ vasectomy acceptors (MOP). This achievement is very far behind when compared to the Jambi Province coverage of $2.5 \%$. This condition illustrates the low participation of men in the family planning program in Muaro Jambi Regency. In order to approach this problem a reference is used from several factors that influence the low proda participation in the family planning program, including predisposing factors, supporting factors and driving factors. The data were collected through a direct interview survey to respondents using a questionnaire and analyzed using a quantitative method with a cross sectional design approach. This study concludes that knowledge is the most dominant factor associated with male participation in family planning programs in Muaro Jambi District. Men with good knowledge about family planning were 2.037 times more likely to participate in family planning programs than men with knowledge

Keywords: Male Participatio; Family Planning; Muaro Jambi
\end{abstract}

How to Cite: Afrinaldi, Y. Suandi. \& Syafri. (2021). Faktor-Faktor Yang Berhubungan Dengan Partisipasi Pria Dalam Program Keluarga Berencana Di Kabupaten Muaro Jambi, PERSPEKTIF, 10(1): 187-194

\begin{tabular}{lr}
\hline$*$ Corresponding author: & ISSN 2085-0328 (Print) \\
E-mail: afrinaldiyun@gmail.com & ISSN 2541-5913 (online)
\end{tabular}




\section{PENDAHULUAN}

Program Keluarga Berencana (KB) merupakan suatu tanggapan praktis paling utama dalam menghadapi masalah kependudukan di Indonesia. Undang-undang Nomor 52 Tahun 2009 tentang Perkembangan Kependudukan dan Pembangunan Keluarga menyebutkan bahwa KB adalah upaya untuk mengatur kelahiran anak, jarak dan usia ideal melahirkan, mengatur kehamilan, melalui promosi, perlindungan dan bantuan sesuai hak reproduksi untuk mewujudkan keluarga yang berkualitas (Kemenkes, 2013b).

Usaha yang luar biasa telah diprakarsai pemerintah dalam melaksanakan program KB. Berkat komitmen pemerintah dan masyarakat yang tinggi, Indonesia pernah sukses menjalankan program KB selama tiga dekade (tahun 1960-1990) dengan secara dramatis menurunkan angka Total Fertility Rate (TFR) dari 5 menjadi 2.8 dan menaikkan angka Contraceptive Prevalence Rate (CPR) dari 5\% menjadi di atas 50\% (Esty, 2012). Semenjak terjadinya perubahan situasi politik tahun 1998 diikuti proses desentralisasi tahun 2004, capaian program KB tersebut mengalami stagnasi pada priode tahun 2002 hingga 2012 yaitu TFR 2.6 dan CPR 61,9\%. Pada tahun 2017, TFR menjadi 2,4 dan CPR sebesar 64\% (SDKI, 2017). Di Provinsi Jambi tahun 2018, angka TFR sebesar 2,47 dan CPR sebesar 57,9\% (BKKBN Provinsi Jambi, 2018).

Kondisi di atas menunjukkan bahwa Indonesia masih memiliki masalah kependudukan yang belum teratasi dan salah satu penyebabnya adalah disparitas kesetaraan gender terkait dengan rendahnya partisipasi pria dalam berkontrasepsi (Saifuddin, 2010a; Larasati, et al., 2018; Ningrum, 2020; Sinurat \& Pinem, M, 2017; Syahnur, et al., 2019). Partisipasi pria merupakan salah satu indikator keberhasilan dalam program KB untuk mewujudkan keluarga kecil berkualitas. Program KB membutuhkan partisipasi pria (suami) tidak hanya untuk mendukung pasangannya dalam berkontrasepsi, namun juga sebagai pengguna langsung kontrasepsi. Pria diharapkan mampu mendukung isteri dalam menentukan pilihan jenis kontrasepsi, persyaratan dan keamanannya, dan faktor lain yang dipertimbangkan dalam KB seperti status kesehatan, efek samping, konsekuensi kegagalan, rencana besar keluarga, persetujuan pasangan, norma budaya lingkungan dan orang tua (Saifuddin, 2010b).

Keberhasilan program KB masa sebelumnya (1960-1990) dan capaian program kesehatan ibu saat ini lebih didukung oleh tingginya peran wanita dan rendahnya partisipasi pria. Data SDKI tahun 2017 mencatat tingkat pemakaian kontrasepsi modern di Indonesia tahun 1991 hingga 2017 berkisar 47,1\% hingga 57,2\%, sedangkan kontribusi pria di dalamnya berkisar hanya $1 \%$ hingga 3\% saja. Data BKKBN Provinsi Jambi mencatat jumlah peserta KB pria tahun 2018 dari 710.319 pasangan usia subur (PUS) hanya sebanyak 17.408 atau 2,5\% sebagai pemakai KB yaitu vasektomi $(0,2 \%)$ dan kondom $(2,3 \%)$. Secara total, proporsi peserta KB pria di tingkat kabupaten/kota berkisar antara 1\% hingga 3,7\%. Kondisi ini menunjukkan partisipasi pria dalam program KB masih sangat minim

Sejalan dengan konsep Green (1991) dalam Notoatmodjo (2014) bahwa partisipasi pria dalam program KB adalah wujud perilaku kesehatan yang bertujuan meningkatkan kualitas kehidupan keluarga, meningkatkan derajat kesehatan ibu, bayi dan anak serta menurunkan angka kematian ibu dan bayi. Perilaku kesehatan dipengaruhi oleh tiga faktor yaitu faktor predisposisi yaitu pengetahuan, sikap, keyakinan, nilai, budaya, dan lain-lain; faktor pendukung yaitu keterampilan, sumber daya, keterjangkauan, kebijakan, dan lain-lain; dan faktor pendorong yaitu dukungan sosial, peran petugas, dan lain-lain (Notoatmodjo, 2014).

Studi Afriandi (2014) melalui analisis data SDKI 2012 menemukan mayoritas partisipasi pria dalam program KB masih rendah dan membuktikan adanya faktor-faktor yang berpengaruh terhadap partisipasi pria tersebut yaitu umur, pendidikan, jenis pekerjaan, jumlah anak masih hidup, pengetahuan alat kontrasepsi sebagai faktor predisposisi, pengetahuan tempat mendapat kondom, paparan media sebagai faktor pemungkin, dan diskusi dengan istri, diskusi dengan dokter sebagai faktor penguat. Hasil yang sama dihasilkan pada riset lainnya yang membuktikan bahwa partisipasi pria dalam KB masih rendah yang dipengaruhi oleh faktorfaktor pengetahuan yang baik, sikap positif, dukungan keluarga (Wahyuni, Suryani, dan Murdani, 2013) serta jumlah anak dan pendapatan (Maharyani dan Handayani, 2010). 
Orientasi pemerintah dalam melaksanakan pembangunan telah mengarah pada kesetaraan dan keadilan gender sesuai Konferensi Internasional tentang Kependudukan dan Pembangunan tahun 1994, namun rendahnya partisipasi pria dalam program KB masih menjadi masalah utama sehingga upaya mensukseskan visi dan misi Pemerintah terkait program KB masih mengalami kendala (Sutinah, 2017) (Permanti dan Purnamasari, 2015). Fenomena ini menjadi dorongan yang menarik untuk diteliti dan tentunya harus menjadi perhatian baik bagi pemerintah daerah maupun masyarakat untuk lebih meningkatkan partisipasi pria dalam program KB guna mewujudkan keluarga yang berkualitas.

Berdasarkan uraian di atas, tujuan peneliti memandang perlu untuk me tentang faktor-faktor yang mempengaruhi partisipasi pria dalam program KB di Kabupaten Muaro Jambi.

\section{METODE PENELITIAN}

Penelitian ini adalah penelitian observasional yang menggunakan metode analitik kuantitatif dengan pendekatan desain cross sectional. Analitik kuantitatif adalah pendekatan penelitian yang fokus pada keakuratan deskripsi setiap variabel dan keakuratan hubungan antar variabel, serta memiliki daerah generalisasi yang luas untuk menjelaskan fakta yang ada (Irawan, 2006) (Utama, Sari dan Ikhtiarini, 2016), sedangkan pendekatan cross sectional yaitu suatu penelitian untuk mempelajari dinamika korelasi antara variabel bebas dan terikat melalui observasi atau pengumpulan data dengan satu kali pengambilan data atau point time approach (Sugiyono, 2014).

Penelitian ini menggunakan sumber data primer melalui survei wawancara langsung Tabel 1. Distribusi Responden Menurut Indikator Partisipasi Pria dalam Program KB di Kabupaten Muaro Jambi

\begin{tabular}{lllll}
\hline \multirow{2}{*}{ Indikator Partisipasi Pria dalam Program KB } & \multicolumn{3}{l}{ Tidak } \\
\cline { 2 - 5 } & Jumlah & $\%$ & Jumlah & $\%$ \\
\hline Menggunakan alat kontrasepsi (KB)? & 27 & 7,1 & 354 & 92,9 \\
Membantu memilih kontrasepsi yang cocok bagi isteri? & 224 & 58,8 & 157 & 41,2 \\
Mengingatkan isteri untuk kontrol ulang KB? & 250 & 65,6 & 131 & 34,4 \\
Mengantar isteri kontrol KB ke fasilitas kesehatan? & 271 & 71,1 & 110 & 28,9 \\
Mencari alternatif KB lain bagi isteri bila KB yang dipakai tidak memuaskan? & 164 & 43,0 & 217 & 57,0 \\
Ikut menghitung waktu subur isteri? & 78 & 20,5 & 303 & 79,5 \\
Membicarakan KB dengan keluarga, teman, atau tetangga dalam 6 bulan terakhir? & 20 & 5,2 & 361 & 94,8 \\
Menjadi kader penggerak KB? & 23 & 6,0 & 358 & 94,0 \\
\hline Sumber: Hasil olahan data primer & & & &
\end{tabular}


Berdasarkan tabel 1. diketahui bahwa proporsi pria yang berpartisipasi secara aktif dalam program KB di Kabupaten Muaro Jambi yaitu sebagai akseptor KB sebanyak 27 orang $(7,1 \%)$ dengan jenis kontrasepsi yang digunakan pria yaitu kondom 26 orang $(6,8 \%)$ dan sisanya MOP 1 orang (0,3\%). Dari 354 pria $(92,9 \%)$ yang tidak ber $\mathrm{KB}$, alasan terbesar adalah karena isteri ber KB sebanyak 292 $(82,5 \%)$, masih ingin punya anak 60 orang $(16,9 \%)$ dan menjawab tidak tahu 2 orang $(0,6 \%)$. Dari tabel tersebut dapat dilihat bahwa partisipasi pria dalam program di Kabupaten Muaro

Selanjutnya variabel partisipasi pria dalam program KB dianalisis menjadi 2 (dua) kategori yaitu partisipasi rendah (< skor 5) dan partisipasi tinggi ( $\geq$ skor 5 ), sebagaimana tabel berikut:

Tabel 2. Distribusi Responden Menurut Partisipasi Dalam Program KB Di Kabupaten Muaro Jambi

\begin{tabular}{lccc}
\hline \multicolumn{2}{l}{ Partisipasi dalam Program KB } & Jumlah & $\%$ \\
\hline - & Rendah \\
- Tinggi & 298 & 78,2 \\
& & & \\
& & 83 & 21,8 \\
\hline \multicolumn{2}{c}{ Total } & 381 & 100 \\
\hline
\end{tabular}

Sumber: Hasil olahan data primer

Berdasarkan tabel 2 diketahui bahwa sebagian besar responden memiliki partisipasi rendah dalam program $\mathrm{KB}$ yaitu sebesar 78,2\%, sedangkan yang memiliki partisipasi tinggi dalam program KB sebesar 21,8\%.

Dari Tabel 1 dan 2 dapat dilihat bahwa secara umum didapatkan bahwa sebagian besar responden memiliki partisipasi yang rendah dalam program $\mathrm{KB}(78,2 \%)$. Hal ini dibuktikan dari indikator pria yang aktif ber KB hanya sebanyak 27 orang $(7,1 \%)$ yaitu menggunakan kondom 26 orang dan MOP 1 orang, sisanya pria tidak ber KB sebanyak 354 $(92,9 \%)$. Kemudian dari 7 indikator lainnya, hanya 3 indikator yang sebagian besar dilakukan oleh pria yaitu memilih kontrasepsi yang cocok bagi isteri (58,8\%); mengingatkan isteri untuk kontrol ulang $\mathrm{KB}(65,6 \%)$; dan mengantar isteri kontrol KB $(71,1 \%)$, sedangkan 4 indikator berikutnya hanya sebagian kecil dilakukan, yaitu mencarikan alternatif KB lain bagi isteri bila KB yang dipakai tidak memuaskan (43\%); ikut menghitung waktu subur isteri (20,5\%); membicarakan KB dengan keluarga, teman, atau tetangga $(5,2 \%)$; dan menjadi kader penggerak KB (6\%).

Untuk menganalisis faktor-faktor yang berhubungan dengan partisipasi pria dalam program KB adalah dengan melakukan analisis bivariat untuk menilai hubungan variabel bebas (partisipasi pria dalam program KB) dengan variabel terikat (umur, pendidikan, pengetahuan, pendapatan, jumlah anak, nilai anak, dan usia pertama kawin) menggunakan uji statistik chi-square dengan derajat kemaknaan $C I$ 95\% $(\alpha=0,05)$.

Tabel 3. menunjukkan bahwa berdasarkan hasil penelitian diperoleh proporsi responden yang berpartisipasi tinggi dalam program KB pada kelompok umur $<40$ tahun sebesar 22,5\%, sedangkan pada kelompok umur $\geq 40$ tahun sebesar 20,8\%. Hasil uji statistik menunjukkan nilai pvalue $=0,695$ yang berarti tidak terdapat hubungan antara umur dengan partisipasi pria dalam program KB. Hasil analisis hubungan pendidikan dengan partisipasi pria dalam program KB diketahui pada kelompok berpendidikan rendah, proporsi responden yang berpartisipasi tinggi dalam program KB sebesar 17,7\%, sedangkan pada kelompok pendidikan tinggi sebesar 24,2\%. Hasil uji statistik menunjukkan nilai $p$-value $=0,142$ yang berarti tidak terdapat hubungan antara pendidikan dengan partisipasi pria dalam program KB.

Hasil analisis hubungan pengetahuan dengan partisipasi pria dalam program KB diperoleh proporsi responden yang berpartisipasi tinggi dalam program KB pada kelompok berpengetahuan kurang baik sebesar $15,2 \%$, sedangkan pada kelompok pengetahuan baik sebesar 26,1\%. Hasil uji statistik menunjukkan nilai $p$-value $=0,012$ yang berarti terdapat hubungan antara pengetahuan dengan partisipasi pria dalam program KB. Hasil analisis hubungan pendapatan dengan partisipasi pria dalam program KB diperoleh pada kelompok berpendapatan rendah $<<2$ juta), proporsi responden yang berpartisipasi tinggi dalam program KB sebesar 25,2\%, sedangkan pada kelompok berpendapatan tinggi ( $\geq 2$ juta) sebesar $24,2 \%$. Hasil uji statistik menunjukkan nilai $p$-value $=0,234$ yang berarti tidak terdapat hubungan antara pendapatan dengan partisipasi pria dalam program KB. 
Hasil analisis hubungan jumlah anak dengan partisipasi pria dalam program KB diperoleh proporsi responden yang berpartisipasi tinggi dalam program $\mathrm{KB}$ pada kelompok jumlah anak > 2 sebesar 24,4\%, sedangkan pada kelompok dengan jumlah anak $\leq 2$ sebesar 19,9\%. Hasil uji statistik menunjukkan nilai $p$-value $=0,022$ yang berarti terdapat hubungan antara jumlah anak dengan partisipasi pria dalam program KB. Hasil analisis hubungan nilai anak dengan partisipasi pria dalam program $\mathrm{KB}$ diperoleh pada kelompok dengan nilai anak $>2$ orang, proporsi responden yang berpartisipasi tinggi dalam program KB sebesar $14,6 \%$, sedangkan pada kelompok dengan nilai anak $\leq 2$ orang sebesar

Tabel 3. Hubungan Faktor-faktor Variabel Bebas dengan Partisipasi Pria dalam Program KB Di Kabupaten Muaro Jambi

\begin{tabular}{|c|c|c|c|c|c|c|c|c|c|}
\hline & \multirow{3}{*}{ Variabel } & \multicolumn{4}{|c|}{ Partisipasi Pria dalam program KB } & \multirow{2}{*}{\multicolumn{2}{|c|}{ Total }} & \multirow{3}{*}{$\begin{array}{l}\text { OR } \\
(95 \% \mathrm{CI})\end{array}$} & \multirow{3}{*}{$\begin{array}{l}\mathrm{p}- \\
\text { value }\end{array}$} \\
\hline & & \multicolumn{2}{|c|}{ Rendah } & \multicolumn{2}{|c|}{ Tinggi } & & & & \\
\hline & & $\mathrm{F}$ & $\%$ & F & $\%$ & $\mathrm{~F}$ & $\%$ & & \\
\hline \multirow[t]{4}{*}{1.} & Umur & & & & & & & \multirow{4}{*}{$\begin{array}{l}0,905 \\
(0,550-1,490)\end{array}$} & \multirow{4}{*}{0,695} \\
\hline & $<40$ tahun & 176 & 77,5 & 51 & 22,5 & 227 & 100 & & \\
\hline & $\geq 40$ tahun & 122 & 79,2 & 32 & 20,8 & 154 & 100 & & \\
\hline & Jumlah & 298 & 78,2 & 83 & 21,8 & 381 & 100 & & \\
\hline \multirow[t]{4}{*}{2.} & Pendidikan & & & & & & & \multirow{4}{*}{$\begin{array}{l}1,479 \\
(0,876-2,496)\end{array}$} & \multirow{4}{*}{0,142} \\
\hline & Rendah & 116 & 82,3 & 25 & 17,7 & 141 & 100 & & \\
\hline & Tinggi & 182 & 75,8 & 58 & 24,2 & 240 & 100 & & \\
\hline & Jumlah & 298 & 78,2 & 83 & 21,8 & 381 & 100 & & \\
\hline \multirow[t]{4}{*}{3} & Pengetahuan & & & & & & & \multirow{4}{*}{$\begin{array}{l}1,964 \\
(1,153-3,346)\end{array}$} & \multirow{4}{*}{$0,012^{*}$} \\
\hline & Kurang Baik & 128 & 84,4 & 23 & 15,2 & 151 & 100 & & \\
\hline & Baik & 170 & 73,9 & 60 & 26,1 & 230 & 100 & & \\
\hline & Jumlah & 298 & 78,2 & 83 & 21,8 & 381 & 100 & & \\
\hline \multirow[t]{4}{*}{4.} & Pendapatan & & & & & & & & \multirow{4}{*}{0,234} \\
\hline & Rendah (< 2 juta) & 101 & 74,8 & 34 & 25,2 & 135 & 100 & \multirow{3}{*}{$\begin{array}{l}0,739 \\
\left(0,449^{-1,217}\right)\end{array}$} & \\
\hline & Tinggi ( $\geq 2$ juta) & 197 & 80,1 & 49 & 19,9 & 246 & 100 & & \\
\hline & $\begin{array}{l}\text { Jumlah } \\
\text { Jumlah Anak }\end{array}$ & 298 & 78,2 & 83 & 21,8 & 381 & 100 & & \\
\hline \multirow{3}{*}{5.} & $>2$ & 223 & 75,6 & 72 & 24,4 & 295 & 100 & \multirow{3}{*}{$\begin{array}{l}0,454 \\
(0,229-0,902)\end{array}$} & \multirow[t]{3}{*}{$0,022^{*}$} \\
\hline & $\leq 2$ & 75 & 87,2 & 11 & 12,8 & 86 & 100 & & \\
\hline & Jumlah & 298 & 78,2 & 83 & 21,8 & 381 & 100 & & \\
\hline \multirow[t]{4}{*}{6.} & Nilai Anak & & & & & & & & \\
\hline & > 2 (Banyak) & 140 & 85,4 & 24 & 14,6 & 164 & 100 & \multirow{3}{*}{$\begin{array}{l}2,178 \\
(1,287-3,687)\end{array}$} & \multirow[t]{3}{*}{$0,003^{*}$} \\
\hline & $\leq 2$ (Cukup) & 158 & 72,8 & 59 & 27,2 & 217 & 100 & & \\
\hline & Jumlah & 298 & 78,2 & 83 & 21,8 & 381 & 100 & & \\
\hline \multirow[t]{4}{*}{7.} & Pertama & & & & & & & & \multirow{4}{*}{0.056} \\
\hline & Kawin & 137 & 74,1 & 48 & 25,9 & 185 & 100 & \multirow{3}{*}{$\begin{array}{l}0,620 \\
(0,380-1,014)\end{array}$} & \\
\hline & $<25$ tahun & 161 & 82,1 & 35 & 17,9 & 196 & 100 & & \\
\hline & $\begin{array}{l}\geq 25 \text { tahun } \\
\text { Jumlah }\end{array}$ & 298 & 78,2 & 83 & 21,8 & 381 & 100 & & \\
\hline
\end{tabular}

Hasil analisis seleksi bivariat dapat dilihat pada tabel berikut ini
$27,2 \%$. Hasil uji statistik menunjukkan nilai pvalue $=0,003$ yang berarti terdapat hubungan antara nilai anak dengan partisipasi pria dalam program KB.

Selanjutnya hasil analisis hubungan usia pertama kawin dengan partisipasi pria dalam program KB diperoleh proporsi responden yang berpartisipasi tinggi dalam program $\mathrm{KB}$ pada kelompok usia pertama kawin $<25$ tahun sebesar 25,9\%, sedangkan pada kelompok dengan usia pertama kawin $\geq 25$ tahun sebesar 17,9\%. Hasil uji statistik menunjukkan nilai pvalue $=0,056$ yang berarti tidak terdapat hubungan antara usia pertama kawin dengan partisipasi pria dalam program KB. 
Tabel 4. Hasil Analisis Seleksi Bivariat Variabel Bebas Dengan Partisipasi Pria dalam Program KB Di

\begin{tabular}{|c|c|c|c|c|}
\hline \multicolumn{5}{|c|}{ Kabupaten Muaro Jambi } \\
\hline No & Variabel & $\begin{array}{l}\text { Log- } \\
\text { Likelihood }\end{array}$ & G & P Value \\
\hline 1. & Umur & 399,264 & 0,154 & 0,695 \\
\hline 2. & Pendidikan & 397,210 & 2,207 & $0,137^{*}$ \\
\hline 3. & Pengetahuan & 392,890 & 6,528 & $0,011^{*}$ \\
\hline 4. & Pendapatan & 398,020 & 1,398 & $0,237^{*}$ \\
\hline 5. & Jumlah Anak & 393,648 & 5,770 & $0,016^{*}$ \\
\hline 6. & Nilai Anak & 390,496 & 8,922 & $0,003^{*}$ \\
\hline 7. & Usia Pertama & 395,756 & 3,662 & $0,056^{*}$ \\
\hline & Kawin & & & \\
\hline
\end{tabular}

Tabel 4. diketahui bahwa variabel yang mempunyai nilai p-wald $>0,05$ atau tidak signifikan dari yang terbesar yaitu variabel pendapatan, jumlah anak, dan pendidikan. Untuk mendapatkan permodelan akhir, variabel yang tidak signifikan dikeluarkan satu persatu yang dimulai dari variabel dengan $\mathrm{p}$ wald terbesar pada setiap analisis dengan memperhatikan perubahan OR $\operatorname{Exp}(\mathrm{B})$ variabel lainnya dalam model. Apabila perubahan OR $\operatorname{Exp}(\mathrm{B}) \leq 10 \%$ maka variabel yang tidak signifikan tersebut dikeluarkan namun jika perubahan OR $\operatorname{Exp}(\mathrm{B})>10 \%$ maka variabel tersebut tetap dimasukkan ke dalam model.

Dalam proses analisis, saat mengeluarkan variabel jumlah anak dan pendidikan menimbulkan perubahan nilai OR $\operatorname{Exp(B)}$ variabel nilai anak $>10 \%$ sehingga variabel jumlah anak dan pendidikan tetap masuk dalam model. Hasil akhir permodelan multivariat dapat digambarkan sebagaimana tabel berikut.

Tabel 5. Hasil Akhir Analisis Multivariat Hubungan Variabel Kandidat Dengan Partisipasi Pria dalam Program KB Di Kabupaten Muaro Jambi

\begin{tabular}{|c|c|c|c|c|c|c|}
\hline No & Variabel & B & $\begin{array}{l}\text { P- } \\
\text { Wald }\end{array}$ & $\begin{array}{l}\text { OR } \\
\operatorname{Exp}(B)\end{array}$ & \multicolumn{2}{|l|}{$95 \% \mathrm{CI}$} \\
\hline \multirow[t]{2}{*}{1.} & Pendidikan & 0,488 & 0,079 & 1,628 & 0,945 & - \\
\hline & Pengetahuan & 0,711 & $0,011^{*}$ & 2,037 & 2,807 & \\
\hline \multirow{8}{*}{$\begin{array}{l}2 . \\
3 . \\
4 . \\
5 .\end{array}$} & Jumlah Anak & 0,579 & 0,136 & 0,561 & 1,174 & - \\
\hline & Nilai Anak & 0,599 & $0,045^{*}$ & 1,821 & 3,535 & \\
\hline & Usia Pertama & 0,626 & $0,017^{*}$ & 0,535 & 0,262 & - \\
\hline & Kawin & & & & 1,199 & \\
\hline & & & & & 1.013 & - \\
\hline & & & & & 3,272 & \\
\hline & & & & & 0,320 & - \\
\hline & & & & & 0,893 & \\
\hline
\end{tabular}

Keterangan : ${ }^{*}=\mathrm{p}<0,05$ (signifikan). Sumber: Hasil olahan data primer

Berdasarkan tabel 5 diketahui bahwa variabel yang memiliki syarat sebagai model terbaik sebagai prediktor partisipasi pria dalam program KB dengan nilai $\mathrm{p}$ wald $<0,05$ adalah variabel pengetahuan, usia kawin pertama dan nilai anak

Setelah memperoleh model terbaik, dilakukan uji interaksi untuk memeriksa kemungkinan adanya interaksi antar variabel di dalam model dengan pertimbangan logika substantif (Hastono, 2006). Hasil uji interaksi dijelaskan pada tabel berikut.

Tabel 6. Hasil Analisis Uji Interaksi

\begin{tabular}{lllll}
\hline No & Variabel & $\begin{array}{l}-2 \text { log- } \\
\text { likelihood }\end{array}$ & P \\
& & & Value \\
\hline 1. & Pengetahuan*Pendidikan & 374,006 & 0,065 & 0,364 \\
2. Jumlah Anak*Nilai Anak & 374,777 & 0,063 & 0,817 \\
3. & Jumlah Anak*Usia & 373,318 & 0,066 & 0,219 \\
& Pertama Kawin & & &
\end{tabular}

Sumber: Hasil olahan data primer

Berdasarkan tabel 6 diketahui bahwa hasil uji interaksi antara variabel yang dianalisis tidak diperoleh nilai $\mathrm{p}<0,05$, berarti dalam model akhir multivariat ini tidak terdapat interaksi antar variabel-variabel tersebut dalam memprediksi partisipasi pria dalam program KB di Kabupaten Muaro Jambi.

Berdasarkan hasil akhir analisis permodelan multivariat (tabel 4.10) diketahui bahwa variabel yang berhubungan secara signifikan dengan partisipasi pria dalam program KB adalah pengetahuan, usia kawin pertama dan nilai anak. Hasil analisis variabel pengetahuan diperoleh nilai OR=2,037 (95\% CI: 1,174 - 3,535) yang disimpulkan bahwa responden dengan pengetahuan baik tentang KB memiliki peluang 2,037 kali untuk lebih berpartisipasi dalam program KB dibanding responden dengan pengetahuan yang rendah setelah dikontrol variabel pendidikan, jumlah anak, nilai anak, dan usia pertama kawin.

Hasil analisis variabel usia pertama kawin diperoleh nilai OR=0,535 (95\% CI: 0,320 - 0,893) dan dapat disimpulkan bahwa responden dengan usia pertama kawin $\geq 25$ 
tahun berpeluang 0,535 kali untuk lebih berpartisipasi dalam program KB daripada responden dengan usia pertama kawin $<25$ tahun setelah dikontrol variabel pengetahuan, pendidikan, jumlah anak, dan nilai anak.

Hasil analisis variabel nilai anak diperoleh nilai OR=1,821 (95\% CI: 1.013 3,272 ) yang berarti bahwa responden dengan nilai anak yang cukup $(\leq 2)$ berpeluang 1,821 kali untuk lebih berpartisipasi dalam program KB dibandingkan responden dengan nilai anak yang banyak $(>2)$ setelah dikontrol dengan variabel pengetahuan, pendidikan, jumlah anak, dan usia pertama kawin.

Selanjutnya dari 3 (tiga) variabel yang berhubungan secara bermakna dengan partisipasi pria dalam program $\mathrm{KB}$, disimpulkan bahwa variabel pengetahuan merupakan faktor yang paling dominan berhubungan dengan partisipasi pria dalam program KB di Kabupaten Muaro Jambi dengan p-value=0,011 dan OR=2,037 (95\% CI: 1,174 3,535), setelah dikontrol oleh variabel pendidikan, jumlah anak, nilai anak, dan usia pertama kawin.

\section{SIMPULAN}

Berdasarkan hasil penelitian maka dapat diambil kesimpulan bahwa partisipasi pria PUS dalam program Keluarga Berencana (KB) di Kabupaten Muaro Jambi tergolong rendah. Selanjutnya, faktor-faktor yang berhubungan dengan partisipasi pria dalam program KB di Kabupaten Muaro Jambi tergolong pada kelompok sumber daya yang tinggi. Faktorfaktor yang berhubungan secara signifikan dengan partisipasi pria dalam program $\mathrm{KB}$ di Kabupaten Muaro Jambi adalah pengetahuan, jumlah anak, dan nilai anak, sedangkan faktor umur, pendidikan, pendapatan, dan usia pertama kawin tidak berhubungan dengan partisipasi pria dalam program KB. Pengetahuan merupakan faktor paling dominan berhubungan dengan partisipasi pria dalam program KB di Kabupaten Muaro Jambi. Pria dengan pengetahuan baik tentang KB berpeluang 2,037 kali untuk lebih berpartisipasi dalam program $\mathrm{KB}$ dibanding pria dengan pengetahuan rendah tentang $\mathrm{KB}$ setelah dikontrol oleh variabel pendidikan, jumlah anak, nilai anak, dan usia pertama kawin.

\section{DAFTAR PUSTAKA}

Afriandi, T., (2014), Faktor-faktor Yang Mempengaruhi Partisipasi Pria Kawin Dalam Keluarga Berencana dan Kesehatan Ibu (Analisis Data SDKI 2012), Tesis, Program Pascasarjana Multidisiplin Kajian Kependudukan dan Ketenagakerjaan, Universitas Indonesia, Depok.

Aryanti, S., Sukmadi, Widyastuti, D., (2019), FaktorFaktor Yang Mempengaruhi Pemilihan Metode Kontrasepsi (Kasus di Kecamatan Seberang Ulu I Kota Palembang), Majalah Geografi Indonesia Vol. 33, No. 1

Febriani, E., (2012), Laporan Analisa Situasi Program KB di Kabupaten, Jakarta.

Hastono, S.P dan Luknis, S., (2010), Statistik Kesehatan, Rajawali Pers, Jakarta.

Irawan, P., (2006), Penelitian Kualitatif dan Kuantitatif untuk Ilmu-ilmu Sosial. DIA FISIP UI, Jakarta.

Kementerian Kesehatan RI, (2013b), Situasi Keluarga Berencana di Indonesia, Buletin Jendela Data dan Informasi Kesehatan, Pusat Data dan Informasi Kementerian Kesehatan RI, Jakarta.

Larasati, Muda, I. Batubara, B.M. \& Suharyanto, A. (2018). Peranan Dinas Pengendalian Penduduk dan Keluarga Berencana dalam Pengendalian Pertumbuhan Penduduk. PERSPEKTIF, 8 (1): 13-18.

Maharyani dan Handayani, S., (2010), Hubungan Karakteristik Suami Dengan Keikutsertaan Suami Menjadi Akseptor Keluarga Berencana Di Wilayah Desa Karangduwur Kecamatan Petanahan Kabupaten Kebumen Jawa Tengah, Jurnal KESMAS Vol. 4, No. 1, page: 175.

Ningrum, D.W.N, (2020). Pengaruh Koordinasi terhadap Efektivitas Pelayanan Kampung Keluarga Berencana Kabupaten Sumedang. PERSPEKTIF, 9 (1): 46-54

Notoatmodjo, S., (2014), Ilmu Perilaku Kesehatan, Cetakan ke-2, Rineka Cipta. Jakarta.

Permanti, P., (2015), Peran Ayah Dalam Pengasuh Anak, Jurnal InSight Vol. 17 No. 2.

Saifuddin, A.B., Affandi, B., Baharuddin, M., dan Soekir, S., (2010b), Buku Panduan Praktis Pelayanan Kontrasepsi, Yayasan Bina Pustaka Sarwono Prawirohardjo, Jakarta.

Saifuddin, A.B., Affandi, B., Baharuddin, M., dan Soekir, S., (2010a), Buku Panduan Praktis Pelayanan Kesehatan Maternal dan Neonatal, PT. Bina Pustaka Sarwono Prawirohardjo, Jakarta.

Sinurat, L., dan Mbina P., (2017), Keadaan Gerakan Keluarga Berencana Di Desa Parlondu Kecamatan Pangururan Kabupaten Samosir. JPPUMA: Jurnal Ilmu Pemerintahan dan 
Yun Afrinaldi, Suandi \& Syafri, Faktor-Faktor yang Berhubungan dengan Partisipasi Pria dalam Program

Sosial Politik UMA (Journal of Governance and Political UMA), 5 (2): 126-138

Sugiyono, (2014), Metode Penelitian Pendidikan Pendekatan Kuantitatif, Kualitatif Dan R\&D, Alfabeta, Bandung.

Sutinah, (2017), Partisipasi Laki-Laki dalam Program Keluarga Berencana di era Masyarakat Postmodern, Jurnal Masyarakat, Kebudayaan dan Politik Vol. 30, No. 3, page: 289 - 299.

Syahnur, S. Diantimala, Y. \& Ilham, R. (2019). Identifikasi Kegiatan Program Kampung Keluarga Berencana di Kabupaten Aceh Tengah. JPPUMA: Jurnal Ilmu Pemerintahan dan Sosial Politik UMA Journal of
Governance and Political Social UMA), 7 (1): 71-79

Utami, J.E.P, Sari. R, Ikhtiarini. E., (2016). Hubungan Peran Seuami Terhadap Pemilihan Jenis Alat Kontrasepsi KB Pada Ibu di Kelurahan Kebonsari Kabupaten Jember, Jurnal Ilmiah Kesehatan Mediahusada, 05(1), 10-20.

Wahyuni, N.P.D.S., Suryani, N., dan Murdani. K.P., (2013), Hubungan Pengetahuan dan Sikap Akseptor KB Pria tentang Vasektomi serta Dukungan Keluarga dengan Partisipasi Pria dalam Vasektomi (Di Kecamatan Tejakula Kabupaten Buleleng), Jurnal Magister Kedokteran Keluarga, 1(1), 80-91. 